\title{
A cross sectional study on prevalence of diarrhoeal disease and nutritional status among children under 5-years of age in Kushtia, Bangladesh.
}

\author{
Afroza Khatun ${ }^{1}$, Sk. Shahinur Rahman ${ }^{*}, 1$, Hafizur Rahman ${ }^{1}$, Sabir Hossain ${ }^{2}$ \\ ${ }^{1}$ Dept. of Applied Nutrition and Food Technology, Islamic University, Kushtia, Bangladesh \\ ${ }^{2}$ Dept. of Biochemistry and Molecular Biology, Jahangirnogor University, Savar, Dhaka, Bangladesh
}

Email address:

shahinanft@gmail.com (Sk. S. Rahman)

To cite this article:

Afroza Khatun, Sk. Shahinur Rahman, Hafizur Rahman, Sabir Hossain. A Cross Sectional Study on Prevalence of Diarrhoeal Disease and Nutritional Status Among Children Under 5-Years of Age In Kushtia, Bangladesh. Science Journal of Public Health. Vol. 1, No. 2, 2013, pp. 56-61. doi: 10.11648/j.sjph.20130102.12

\begin{abstract}
Children under 5 years old are most vulnerable and high risk group who need special health care services. Because infectious diseases, diarrhea, malnutrition etc are very common in this group. This study was carried out among the total of 400 children in Kushtia from January 2008 to December 2008 and observed the prevalence of diarrhoea among them. A cross sectional survey was carried out to determine nutritional status of under-5years children by anthropometric measurement, MUAC measurement and bio-chemical assessment. Anthropometric measurements were performed by standard methods National Centre for Health Statistics (NCHS) of the United States. Amongst all the children higher proportion of children $47 \%$ were found to be malnourished (under weight) using W/A as indicator in the age range of $0-60$ months. Amongst all the subjects' prevalence of wasting and stunting was $51 \%$ and $49 \%$ respectively. Age group $0-12$ months shows the highest prevalence of wasting, under weight and stunting. The prevalence of diarrhoea was found $44.5 \%$. The maximum prevalence (48.86\%) and frequency (1.7) of diarrhoea was present in 12-24 months of age. Factors that influence malnutrition and frequency of diarrhea were limited access to sanitation facilities, unhygienic water drinking and handling, mother's education, misconception about food, infectious diseases and weaning practices. These results suggested that improving nutritional status of urban poor requires direct, focused and integrated strategies that are preferably community based and involve the behavior modification by education in addition to providing comprehensive preventive and curative health and nutritional services.
\end{abstract}

Keywords: Diarrhoea, Malnutrition, Anthropometric measurement, Children under 5 years, Kushtia

\section{Introduction}

Diarrhoea is one of the major factors that contribute significantly to high child morbidity and mortality in many developing countries. ${ }^{[1]}$ Among children under 5 years old, about $17 \%$ of all deaths occur due to Diarrhoea. ${ }^{[2]}$ Annually, at least 1,500 million episodes of diarrhoea occur in this group and about 4 million children's death occur due to diarrhoea. ${ }^{[3]}$ Among the causative agents, the following bacteria have been reported: enterotoxigenic Escherichia coli (ETEC), Shigella, Salmonella, and Campylobacter. ${ }^{[4,5]}$ Among the viruses, rotavirus seems to be the most common. ${ }^{[6]}$ In developing countries, diarrhoeal infections under 5 years child are generally associated with rotavirus often at the time of weaning. ${ }^{[7]}$ The infectious agents associated with diarrhoeal disease are transmitted chiefly through the faecal-oral route. ${ }^{[8,2]}$ Food contamination is one major route for the transmission of enteropathogens, especially under the hygienic conditions prevailing in a rural setting. Various studies have reported that the source of enteropathogens was either water or food. ${ }^{[9,10]}$ For most people in developing countries, the major source of food is cereals, and dairy products are limited to a very small segment of affluent groups. Presumably, the reports of food as the origin of diarrhoea refer to cereal- based diets, since all the cases cited came from developing countries. ${ }^{[11,12]}$ Diarrhoea is an intestinal disorder characterized by abnormal fluidity and frequency of fecal evacuations, generally the result of increased motility in the colon; may be an important symptom of such underlying disorders as dysenteric diseases, lactose intolerance GI tumors and inflammatory bowel disease. Yet 
diarrhoeal illnesses in young children continue to be a leading cause of morbidity and mortality worldwide. ${ }^{[13]}$ Every year around 10 million children under 5 die: about half of these deaths are associated with under nutrition and about 2 million with diarrhoea (out of a total of 2.5 billion episodes of diarrhoea). Most mortality related to diarrhoea occurs in less developed countries, and the highest rates of diarrhoea occur among malnourished children. ${ }^{[10]}$ The case fatality rate is highest among children aged 6-12 months because at this age the immune system is not yet fully mature, maternal antibodies are waning, and the foods introduced to complement breastfeeding may be contaminated. The synergistic effect of poor nutritional status and diarrhea on immunity to infection has been well described ${ }^{[14]}$ Poor nutrition adversely affects a child's ability to resist or respond to infection, and infection adversely affects a child's appetite and ability to effectively use energy and nutrients obtained from the diet. The extent to which immunity is impaired is likely to vary with seasonal nutrient intake and distribution of infectious diseases. ${ }^{[15,16]}$ Although the effectiveness of oral rehydration therapy has been proved, only about $20 \%$ of children with diarrhoeal episodes worldwide currently receive it appropriately. ${ }^{[17]}$ Furthermore, knowledge and use of appropriate home treatments to manage diarrhoea successfully may be declining. Adherence to recommendations for children is poor because oral rehydration therapy does not reduce the duration of diarrhoea: this often leads to use of antibiotics and other treatments of no proved value. The continued high morbidity, mortality, and malnutrition associated with diarrhoeal diseases have led to a search for adjunctive treatments. Numerous randomized controlled trials have shown the therapeutic benefits of zinc supplementation during diarrhoea and WHO and UNICEF have recently recommended the therapeutic use of zinc for 10-14 days at a dose of $10 \mathrm{mg}$ daily in infants less than 6 months old and $20 \mathrm{mg}$ daily in older children. ${ }^{[18]}$ The effectiveness of different delivery strategies for zinc is currently being evaluated. Thus the clinical management of acute diarrhoea has four main components: replacement of ongoing losses of fluid and electrolytes, zinc therapy, antimicrobial therapy when indicated, and continued feeding to supply enough nutrients to meet both the patient's usual maintenance requirements and the increased needs imposed by infection and malabsorption.

\section{Methods and Materials}

This cross sectional descriptive analytical study is done in rural and urban areas of Kushtia district, in the year 2008. Pre-school children under-5 years of age were selected randomly. This study cover 400 children (boys 209, girls 191) aged between 0-60 months and the data were collected via standard questionnairies, mother interview, anthropometric measurements such as- weight, height, age, MUAC and dietary history of both mother and children.
Data was coded and entered into a computer database, summarized and presented descriptively. Z-scores were calculated for height-for-age (H/A), weight-for-height $(\mathrm{W} / \mathrm{H})$ and weight-for-age (W/A) using Epi Info software. Prevalence of stunting, wasting and underweight was determined using $<-2$ of $\mathrm{H} / \mathrm{A}, \mathrm{W} / \mathrm{H}$ and $\mathrm{W} / \mathrm{A}$, respectively of the National Centre for Health Statistics (NCHS) reference standards. The figures therefore represent malnutrition, prevalence and frequency of diarrhea in each category. Relationships among nutritional variables, birth weight and parental education etc were analyzed using Spearman's Chi square test using SPSS software.

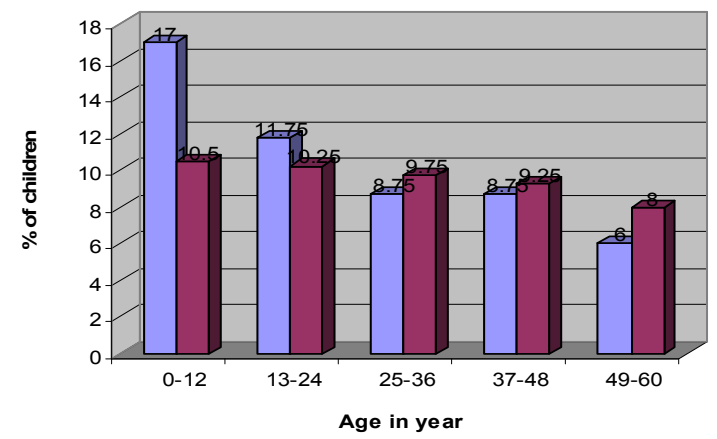

Figure 1. Percent distribution of children according to age and sex.

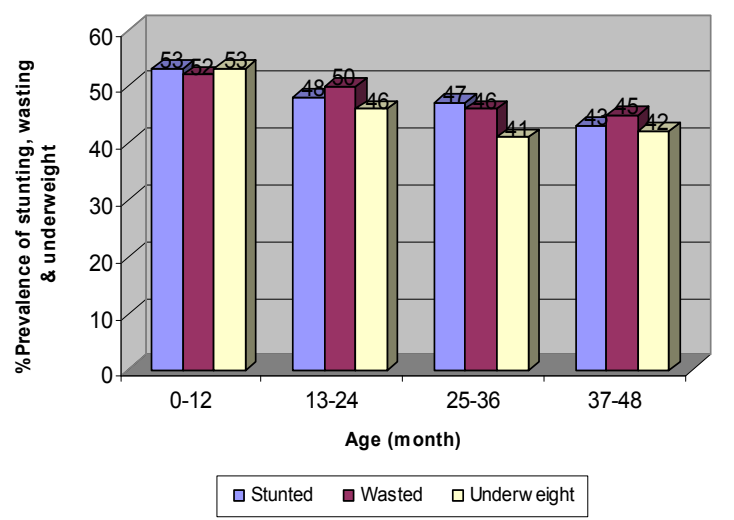

Figure 2. Percent prevalence of stunting, wasting and underweight by age group for survey.

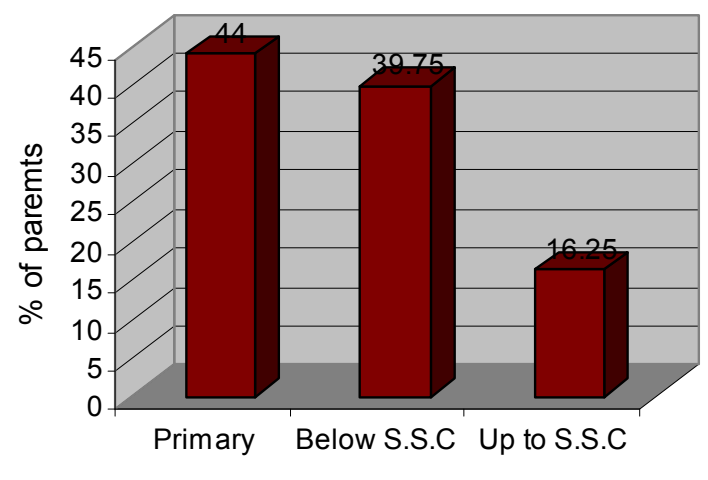

Level of education

Figure 3. Percent distribution of parents by educational status.

\subsection{Data Analysis}




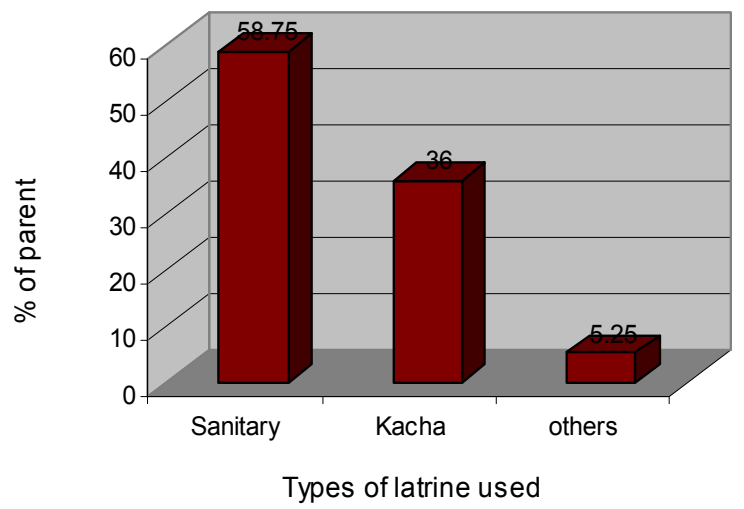

Figure 4. Percent distribution of parents by the type of latrine used.

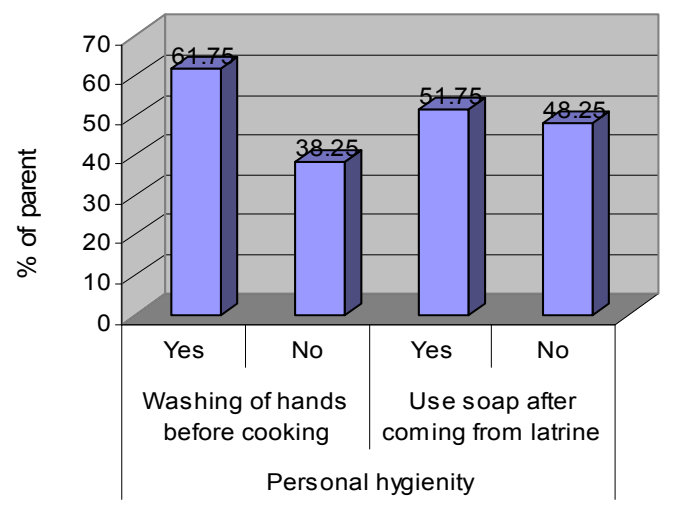

Figure 5. Percent distribution of parents based on personal hygienity.

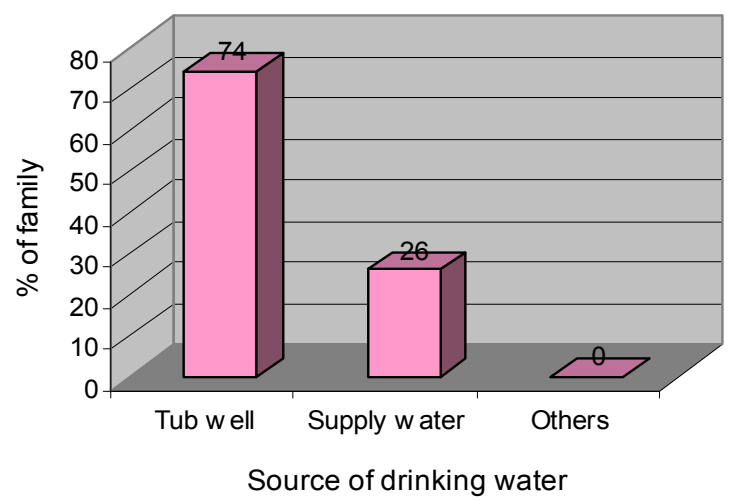

Figure 6. Percent distribution of family by source of drinking water

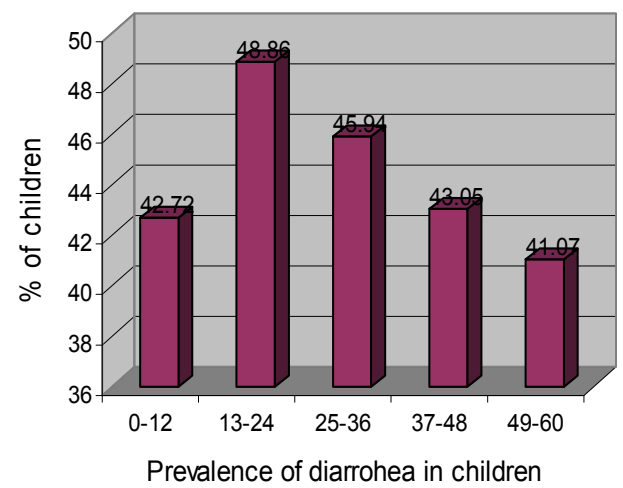

Figure 7. Percent distribution of children's by suffering diarroheal disease according to age group

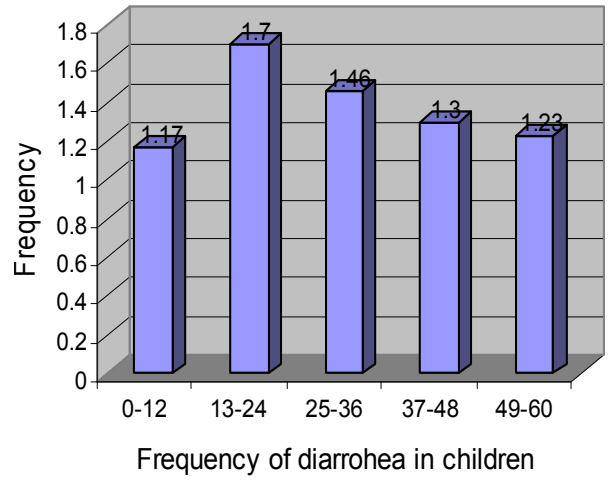

Figure 8. Distribution of children's diarrohea frequency according to age group

\section{Results}

This study was carried out among the total of 400 rural and urban children (boys 209, girls 191) under five years old in Kushtia district from January 2008 to December 2008 and observed the prevalence of diarrhoea among them with special reference to the socioeconomic status of parents. Distribution of children by age, sex, family size, family income, educational qualification of parents, and types of house are being depicted in this phase.

Table 1 showed the distribution of children according to age and sex, Children's age was in a range of 0-60 months with a mean of 31.12 months. Amongst 400 children, $52.25 \%$ were male and $47.75 \%$ were female, highest number $27.50 \%$ of children were in the age group 0-12 months. Percentage of children in age group of 13-24, 25-36, 37-48 and 49-60 months were $22 \%, 18.50 \%, 18 \%$ and $14 \%$ respectively.

Table 1. Distribution of Children According to Age and Sex.

\begin{tabular}{|c|c|c|c|c|}
\hline \multirow{3}{*}{$\begin{array}{l}\text { Age (month) } \\
0-12\end{array}$} & \multicolumn{3}{|c|}{ Sex of the children } & \multirow[b]{2}{*}{$\begin{array}{l}\text { Mean age } \\
\text { (month) }\end{array}$} \\
\hline & $\begin{array}{l}\text { Number } \\
\text { of male (\%) }\end{array}$ & $\begin{array}{l}\text { Number } \\
\text { of female (\%) }\end{array}$ & $\begin{array}{l}\text { Total } \\
\text { number }\end{array}$ & \\
\hline & $68(17.00)$ & $42(10.50)$ & $110(27.50)$ & \multirow{6}{*}{31.12} \\
\hline $13-24$ & $47(11.75)$ & $41(10.25)$ & $88(22.00)$ & \\
\hline $25-36$ & $35(8.75)$ & $39(9.75)$ & $74(18.50)$ & \\
\hline $37-48$ & $35(8.75)$ & $37(9.25)$ & $72(18.00)$ & \\
\hline $49-60$ & $24(6.00)$ & $32(8.00)$ & $56(14.00)$ & \\
\hline Total & $209(52.25)$ & 191(47.75) & $400(100.00)$ & \\
\hline
\end{tabular}

Number in parenthesis indicates the percentage of the children.

Nutritional anthropometry revealed that $49 \%$ of the children aged less than 5 years were stunted, $47 \%$ were under-weight, and 51\% were wasted. Age group 0-12 months shows the highest prevalence of wasting, under weight and stunting.

Table depicts that $44.00 \%$ of the parents had no formal primary education, $39.75 \%$ received education below S.S.C. and $16.25 \%$ Received education up to S.S.C. same pattern exists for both short term and long term malnutrition, with 
parents educational qualification is strongly linked to the nutritional status of her children.

Table 2. Distribution of Children's by Percent Incidence of Stunting, Wasting and Underweight According to Age Group.

\begin{tabular}{llll}
\hline Age (months) & \begin{tabular}{l} 
Stunted \\
\cline { 2 - 4 }$\left(\begin{array}{l}\text { WSD } \\
\text { or below) }\end{array}\right.$
\end{tabular} & $\begin{array}{l}\text { (-2SD } \\
\text { or below) }\end{array}$ & $\begin{array}{l}\text { (-2SD or } \\
\text { below) }\end{array}$ \\
\hline $0-12$ & 53 & 52 & 53 \\
$13-24$ & 48 & 50 & 46 \\
$25-36$ & 47 & 46 & 41 \\
$37-48$ & 43 & 45 & 42 \\
$49-60$ & 47 & 43 & 49 \\
Total & 49 & 51 & 47 \\
\hline
\end{tabular}

Table 3. Distribution of Parents by Educational Status.

\begin{tabular}{|c|c|c|}
\hline Level of education & No of parent & $\%$ of parent \\
\hline Primary & 176 & 44.00 \\
\hline Below S.S.C & 159 & 39.75 \\
\hline Up to S.S.C & 65 & 16.25 \\
\hline
\end{tabular}

Table 4. Distribution of Latrine Used by the Household.

\begin{tabular}{lll}
\hline Type of latrine used & No of parent & \% of parent \\
\hline Sanitary & 235 & 58.75 \\
Kacha & 144 & 36.00 \\
others & 21 & 5.25 \\
\hline
\end{tabular}

Table shows the distribution of parents by the type of latrines used. Most of the study subjects used the sanitary latrines. That is $36.00 \%$ of had kaccha and $58.75 \%$ had sanitary latrines.5.25\% used others. Type of latrine Proportion stunted is in households using sanitary latrines. Chronic malnourishment appears to be even higher in households with no access to toilet facilities.

Table 5. Distribution of Mothers Based on Personal Hygienity

\begin{tabular}{|c|c|c|c|c|}
\hline \multirow{3}{*}{$\begin{array}{l}\text { Total } \\
\text { Number } \\
\text { of mothers }\end{array}$} & \multicolumn{4}{|c|}{ Personal hygienity } \\
\hline & \multicolumn{2}{|c|}{$\begin{array}{l}\text { Washing of hands before } \\
\text { cooking }\end{array}$} & \multicolumn{2}{|c|}{$\begin{array}{l}\text { Use soap after } \\
\text { coming from latrine }\end{array}$} \\
\hline & Yes & No & Yes & No \\
\hline 400 & $\begin{array}{l}247 \\
(61.75 \%)\end{array}$ & $\begin{array}{l}153 \\
(38.25 \%)\end{array}$ & $\begin{array}{l}207 \\
(51.75 \%)\end{array}$ & $\begin{array}{l}193 \\
(48.25 \%)\end{array}$ \\
\hline
\end{tabular}

From the above table, it has been shown that most of the mothers $(61.75 \%)$ wash their hands before cooking and use soap $(51.75 \%)$ after coming from latrine. It has been also shown that few mothers $(38.25 \%)$ are not wash their hands before cooking and use soap (48.25\%) after coming from latrine.
Table 6. Distribution of Parent by Source of Drinking Water.

\begin{tabular}{lll}
\hline Source of drinking water & No of parent & \% of family \\
\hline Tub well & 296 & 74 \\
Supply water & 104 & 26 \\
Others & - & - \\
\hline
\end{tabular}

Table -shows $74 \%$ of households use tube well water for drinking and $26 \%$ of households use supply water for drinking.

Table 7 shows percentage of diarrhea according to age group. $42.72 \%$ were in the age range of $0-12$ month and $48.86 \%, 45.94 \%, 43.05 \%, 41.07 \%$, were in the age range of 13-24, 25-36, 37-48, and 49-60 month respectively.

Table 7. Distribution of Children's by Suffering Diarroheal Disease According to Age Group.

\begin{tabular}{lcc}
\hline Age & No. of Children & Prevalence (\%) \\
\hline $0-12$ & 47 & 42.72 \\
$13-24$ & 43 & 48.86 \\
$25-36$ & 34 & 45.94 \\
$37-48$ & 31 & 43.05 \\
$49-60$ & 23 & 41.07 \\
Total & 178 & 44.50 \\
\hline
\end{tabular}

Table 8 shows the frequency of diarrohea according to age group 1.17 were in the age range of $0-12$ month and 1.70 , $1.46,1.30$, and 1.23 were in the age range of $13-24,25-36$, 37-48, and 49-60 month respectively.

Table 8. Distribution of Children's Diarroheal Frequency According to Age Group.

\begin{tabular}{ll}
\hline Age (months) & Frequency \\
\hline $0-12$ & 1.17 \\
$13-24$ & 1.70 \\
$25-36$ & 1.46 \\
$37-48$ & 1.30 \\
$49-60$ & 1.23 \\
\hline
\end{tabular}

\section{Discussion}

Mortality and morbidity are high under five years children. About $12.5-15 \%$ of world population are in this age group. In developing countries, $25-30 \%$ of mortality occurs in this group. ${ }^{[19-24]}$ Among the major life threatening infectious diseases diarrhoea is one of the major preventable gastrointestinal health problem. Risk factors for diarrhoea include malnutrition, poor gastrointestinal absorption, poor personal hygiene, environmental sanitation problems, unhygienic food preparation, improper sewage disposal and improper use of latrines, early discontinuation of breastfeeding, and unhygienic bottle-feeding. ${ }^{[25,26]}$ Prevalence of diarrhoea is quite alarming amongst our children who belong to low socioeconomic status. According to UNICEF and the World Health Organization (WHO), diarrhoea kills more children than any other illness - more than AIDS, 
malaria and measles combined. Effective interventions to reduce diarrhea deaths are available, but reach too few children. Reducing child mortality is one of the eight Millennium Development Goals (MDGs), which are the world's time-bound targets for reducing poverty in its various dimensions by 2015. Achieving this goal will require urgent action to reduce childhood diarrhoea deaths, which at present account for 19 percent of all under-five deaths. ${ }^{\text {[27] }}$ This cross sectional study was carried out by survey of dwelling condition, face to face interviews with the mother and examination of physical condition and different reports of hospital and diagnostic centre of children aged less than 5 years. Multivariate models were developed to calculate the prevalence for diarrhea among the malnourished children and their association with various aspects such as of demographic, socioeconomic, health and community factors. Household, environment and personal hygiene related factors are important contributors to the occurrence of diarrhea. We examined these factors in relation to the occurrence of persistent diarrhoea. Moderate-to-strong association of selected household environmental factors with the occurrence of persistent diarrhoea included absence of a latrine and pump-water supply. Others have found a similar association of these environmental factors with the occurrence of diarrhoea, including persistent illness. Anthropometric measurements were performed by standard methods (NCHS), and MUAC measurement. Parents educational qualification is strongly linked to the nutritional status of her children. In our study at Kushtia, $44.0 \%$ of the parents had no formal primary education and only $16.25 \%$ had completed Secondary Certificate. Amongst the study population $39 \%$ families lived in semipacca (tinshed) house, whereas $26.25 \%$ in kaccha (mudshed) and only $34.75 \%$ had pacca house (buildings) to live in. Most of the study subjects used the sanitary latrines $(58.75 \%)$ whereas $36 \%$ of had kaccha (unsanitary) latrines. In our study, $74 \%$ of the households use tube well water for drinking and none of them boil water before drinking. About $65 \%$ mother feed their children with their own hand but they don't use soap for washing their hand. $30 \%$ children consume food with their own hand and among of them only $35 \%$ don't wash their hand before eating. Source of drinking water whether safe or unsafe, has negligible impact on short term malnourishment of pre-school children. Diarrhoea has been reported to occur among all age groups particularly in the developing countries and has been highly prevalent among children in the first two years of life. In our study, nutritional anthropometry revealed that $49 \%$ of the children aged less than 5 years were stunted, $47 \%$ were under-weight, and $51 \%$ were wasted. The prevalence of diarrhoea was found $44.5 \%$. The maximum prevalence $(48.86 \%)$ and frequency $(1.70)$ of persistent diarrhea was present in 12-24 months of age. A high prevalence of persistent diarrhoea among the young infants in our study may be related to the early exposure to heavy microbial load and immaturity of the gut immune system at early infancy. In the present study, persistent diarrhoea was positively associated with more intense diarrhoea. Significantly more infants progressed to persistent diarrhoea, passing 10 or more unformed stools in the first day of illness. The stools passed were more likely to be watery in consistency and to contain mucus. However, acute diarrhoea due to bacteria infections is an important cause of morbidity and mortality in infants and young children in most developing countries including Bangladesh.

\section{Conclusions}

In our study, the high prevalence of diarrhoea are suspected and reported in Kushtia district. So, the authors recommend frequent nutritional survays and targeting persons are displaced to better understand the causes of diarrhea In addition to poverty alleviation, action must be addressed to the underlying factors of food security, food safety, social status, gender discrimination, women's education, housing, adequate healthcare practice, supply of portable water and sanitation.

\section{Acknowledgement}

The authors are thankful to the Dept. of Applied Nutrition and Food Technology and to the participants of this study at Kushtia who shared their valuable time to fill their oral questionnaire and various types of anthropometric measurement.

\section{References}

[1] UNICEF. The state of the world's children 1988. Oxford; UK: Oxford University Press, 1988.

[2] Onyango and Angienda. Epidemiology of Waterborne Diarrhoeal Diseases among Children Aged 6-36 Months Old in Busia - Western Kenya. International Journal of Biological and Life Sciences 6:2 2010

[3] WHO. Selected publications and documents on diarrhoeal diseases (including cholera), 1999. url:http//www.who.int/aboutwho/en/preventing/preventing.h tm.

[4] Black RE, Huq I, Merson MH, Alim A, Yunus MD. Incidence and severity of rotavirus and E. coli diarrhoea in rural Bangladesh. Lancet 1981;1:141-43.

[5] Suan GJ, Rowland GDH, Lloyd-Evans N. Williams K, Rowland, MM. The etiology of diarrhoea studied in the community in young urban Gambian children. J Diarrhoeal Dis Res 1985;3(1):7-13.

[6] Black RE, Merson MH, Rahman ASMM et al. A two year study of bacterial, viral and parasitic agents associated with diarrhoea in rural Bangladesh. J Infect Dis 1980;142:66064.

[7] D. Rogers, J. McEwen, R. Beaglehole and H. Tanaka, "The practice of public health",Oxford text book of Public Health; 4th ed. 2002.

[8] K. E. Byers, R. L. Guerrant, B. M. Farr, Fecal-oral transmission, In: Thomas JC, Webber DJ editor(s). "Epidemiologic methods for the study of infectious disease". Oxford Uni- 
versity Press. 228-48, 2001.

[9] [9] Rowland MOM, Barrel RAE, Whitehead RG. Bacterial contamination in traditional Gambian weaning foods. Lancet 1978;1:136-38.

[10] Black RE, Morris SS, Bryce J. Where and why are 10 million children dying every year? Lancet 2003;361: 2226-34.

[11] Chen LC, Scrimshaw NS, eds. Diarrhea and malnutrition. New York: Plenum Press, 1983:319.

[12] Mathur R. Reddy V. Bacterial contamination of infant foods. Ind J Med Res 1983;77:342-46.

[13] www.who.int/mediacentre/factsheets/fs330/

[14] Scrimshaw NS, SanGiovanni JP. Synergism of nutrition, infection, and immunity: an overview. Am J Clin Nutr 1997;66: 464S-77S.

[15] Victora CG, Kirkwood BR, Ashworth A, et al. Potential interventions for the prevention of childhood pneumonia in developing countries: improving nutrition. Am J Clin Nutr 1999; 70:309-20.

[16] O'Dempsey TJ, McArdle TF, Morris J, et al. A study of risk factors for pneumococcal disease among children in a rural area of west Africa. Int J Epidemiol 1996;25:885-93.

[17] Jones G, Steketee RW, Black RE, Bhutta ZA, Morris SS, Bellagio Child Survival Study Group. How many child deaths can we prevent this year? Lancet 2003;362: 65-71.

[18] Clinical management of acute diarrhoea. WHO/Unicef joint statement. United Nations Children's Fund, World Health
Organization, 2004. (WHO/FCH/CAH/04.7.)

[19] [19] Park JA and Park V(1996): Parks textbook: Preventive $\&$ social medicine, (translation by shogaei \& others), Vol 3, Tehran, 2nd ed.

[20] Blount BW and et al. (1993): Nutritional states of rural Bolivian children, Military Medicine, 158:20-4.

[21] Behrman RE (2000): Nelson, textbook of pediatrics, $16^{\text {th }}$ ed, Saunders company.

[22] F Majlesi, B Nikpoor, B Golestan , F Sadre. Growth Chart Study in Children Under 5 Years Old in Rural Area of Khoramabad Province. Iranian J. Publ. Health, Vol. 30, Nos. 3-4, PP. 107-110, 2001

[23] Aldana MJ and Piechulek H (1992): Nutrition states of 0-59 months old childern in urban and rural areas of cameron, Bull WHO, Vol 70

[24] Grant GP (1988): Children situation in world. World Health, (translation by Hoseiny) Tehran.

[25] Black RE, Lanata CF. Epidemiology of diarrheal diseases in developing countries. In : Blaser MJ, Smith PD, Ravdin JI, Greenberg HB, Guerrant RL, editors. Infections of the gastrointestinal tract. New York: Raven Press, 1995:13-36.

[26] Brown KH, Black RE, de Romana GL, de Kanashior HC. Infant-feeding practices and their relationship with diarrheal and other diseases in Huascar (Lima), Peru. Pediatrics 1989;83:31-40.

[27] UNICEF/WHO. Pneumonia: The forgotten killer of children. 2006 